\title{
Heinrich Rickert e a fundamentação (axio)lógica do conhecimento histórico***
}

\section{Heinrich Rickert and the (Axio)logical Foundations of Historical Knowledge}

\author{
SÉRGIO DA MATA \\ Doutor em História pela Universidade de Colônia \\ Prof. Adjunto. UFOP. Dep. de História \\ Rua do Seminário, s/no, Centro, Mariana/MG, CEP 35420-000 \\ sdmata@gmx.de
}

\begin{abstract}
RESUMO Heinrich Rickert foi uma das figuras de maior prestígio da filosofia neokantiana na passagem dos séculos XIX-XX. Sua grande contribuição no sentido de dar uma fundamentação lógica às Kulturwissenschaften em geral, e à ciência histórica em particular, caiu no esquecimento. Nos últimos tempos, com o anúncio do "fim" da epistemologia e o aparente triunfo do solipsismo pós-moderno, parece-nos oportuno retornar a Rickert e restabelecer um diálogo com sua obra.
\end{abstract}

Palavras-chave Rickert, teoria da história, neokantismo.

\footnotetext{
* Artigo recebido em 17/02/2006. Autor convidado.

* Uma versão inicial deste trabalho foi apresentada no III Colóquio Nacional de Filosofia da História (Aracajú 23-25.08.2005). Agradecemos pelo apoio financeiro que nos foi prestado pela FAPEMIG e pela Pró-reitoria de Pós-graduação e Pesquisa da UFOP.
} 
ABSTRACT Heinrich Rickert was one of the most renowned neokantian philosophers of the late $19^{\text {th }}$ to early $20^{\text {th }}$ centuries. His great contribution in establishing a logical foundation both to the so-called Kulturwissenschaften and to the historical knowledge of his time had fallen in oblivion. In the last years, with the announcement of the "end" of the epistemology and the apparent victory of the post-modern solipsism, it seems appropriate to reevaluate Rickert's contributions reestablishing a dialogue with his work.

Key words Rickert, Theory of History, Neokantism.

\section{Introdução}

Da geração de filósofos neokantianos de fins de século XIX e inícios do XX, Heinrich Rickert foi uma das figuras de maior prestígio. Discípulo e ex-aluno de Wilhelm Windelband, ele exerceu forte influência à época. Historiadores tão diferentes entre si como Karl Lamprecht, Georg von Below, Eduard Meyer, Max Weber, Ernst Troeltsch e Johan Huizinga estabeleceram um diálogo crítico com sua obra.

O silêncio atual em torno de Rickert não é gratuito nem recente. Em um inspirado diagnóstico crítico da sociedade industrial, originalmente publicado em 1949, Arnold Gehlen observou que "a era do lluminismo terminou, e com ela a crença na necessidade de uma conceituação cada vez mais precisa e abstrata". ${ }^{1}$ Mais de cinqüenta anos depois, estas palavras permanecem atuais. Elas nos ajudam a compreender por que Rickert foi relegado ao esquecimento. Ainda nos anos 1930, Aron se referia às suas posições nestes termos: sa pensée est morte, appartient au passé. ${ }^{2}$ Após o fim da segunda grande guerra, alguns dos mais conhecidos filósofos alemães (Jaspers, Heidegger, Gadamer) mantiveram uma postura ostensiva em relação à sua obra.

Tudo isso não deixa de ser paradoxal se observarmos que Weber - autor que bem poderíamos qualificar de "rickertiano" — viria a ter um destino completamente diverso. À medida em que Weber ganhava o mundo, muito se falou e escreveu sobre sua sociologia compreensiva, mas pouco, surpreendentemente pouco, sobre a grande importância que ele conferia à adequada fundamentação lógica das "ciências da realidade". Embora Weber não tenha estabelecido uma hierarquia entre explicação e compreensão, manifesta-se entre muitos de seus intérpretes aquilo que Merz acertadamente chamou de reificação do problema da compreensão (Hypostasierung des

1 GEHLEN, Arnold. Die Seele im technischen Zeitalter. Sozialpsychologische Probleme in der industriellen Gesellschaft. Hamburg: Rowohlt, 1957, p. 35.

2 ARON, Raymond. La philosophie critique de l'histoire. Essai sur une théorie allemande de l'histoire. Paris: J. Vrin, 1969, p. 139. 
Verstehensproblems). ${ }^{3}$ As inúmeras e profundas afinidades eletivas entre Rickert e Weber ficaram, assim, cada vez mais difíceis de visualizar. ${ }^{4}$

Uma das principais realizações de Rickert foi elaborar uma fundamentação rigorosa para as ciências culturais no plano lógico-conceitual. Nesta perspectiva, a diferença principal em relação às ciências da natureza não deveria ser buscada nos objetos aos quais umas e outras se devotam, mas nos procedimentos adotados. O que se opõe ao "natural" não é o "espiritual", diz Rickert, mas o "histórico" (entendido aqui enquanto evento ou realidade singular). A teorização de Dilthey sobre as "ciências do espírito" fora um grande passo, mas deixava de elucidar as características próprias daquilo que Rickert chamou territórios intermediários. ${ }^{5}$ Casos como da psicologia e da história natural. A primeira, embora seja uma disciplina devotada ao estudo dos fenômenos psíquicos (relativos ao "espírito", portanto), adota, em grande parte, procedimentos típicos das ciências naturais. Ela busca generalizações, persegue "leis". A segunda, por sua vez, estuda a evolução da vida na face da terra, e isso numa perspectiva próxima das ciências culturais - ela estuda a vida na sua historicidade. Basta ainda citar títulos de obras que ganharam notoriedade no último século, como $O$ Mediterrâneo no tempo de Felipe Il ou História do clima depois do ano 1000,

3 MERZ, Peter-Ulrich. Max Weber und Heinrich Rickert. Die erkenntniskritischen Grundlagen der verstehenden Soziologie. Würtzburg: Königshausen \& Neumann, 1990, p. 41. Comentando a indissociabilidade dos dois postulados em Weber, Eberle observa que "demonstrações sociológicas devem ser não apenas adequadas quanto ao sentido (sinnadäquat), mas também quanto às causas (kausaläquat)". Cf. EBERLE, Thomas. Sinnadäquanz und Kausaladäquanz bei Max Weber und Alfred Schütz. In: HITZLER, Ronald; REICHERTZ, Jo; SCHORER, Norbert (Hrsg.) Hermeneutische Wissenssoziologie. Konstanz: UVK, 1999, p. 97.

4 Tomemos o exemplo de duas obras recentes: DOMINGUES, Ivan. Epistemologia das ciências humanas. São Paulo: Loyola, 2004; e RINGER, Fritz. A metodologia de Max Weber. São Paulo: Edusp, 2004. Nas mais de oitenta páginas em que discute o "método das ciências histórico-sociais" em Weber, Domingues não dedica sequer um parágrafo a Rickert. Vejamos o que nos diz Guy Oakes a respeito: "Grande parte do vocabulário filosófico que Weber emprega em seus escritos metodológicos é tomado de empréstimo a Rickert, por exemplo a noção de irracionalidade do real, a idéia de um hiatus irrationalis entre conceito e realidade, e conceitos como os de individualidade histórica e relação de valor. [...] A crítica de Weber ao positivismo, sua diferenciação lógica entre ciências culturais e naturais, sua divisão entre juízos de valor práticos e relações teóricas de valor, e ainda sua visão da metodologia como uma doutrina de formação de conceitos - tudo isso baseia-se em argumentos minuciosamente apresentados na obra de Rickert". OAKES, Guy. Die Grenzen kulturwissenschaftlicher Begriffsbildung. Frankfurt am Main: Suhrkamp, 1990 p. 15. Sobre o mesmo assunto, ver também WÖHLER, Sven. Das heterologische Denkprinzip Heinrich Rickerts und seine Bedeutung für das Werk Max Webers. Tese de doutorado, Universität Erfurt, 2001. Estranhamente, Domingues escreve em seu livro que Weber "nunca perdoou aos amigos Windelband e Rickert pelo fato de terem prejudicado a carreira universitária do colega [Simmel], quando se viu perseguido por ser judeu" (p. 392). Tal afirmação é no mínimo fantasiosa. Pois: (I) o que havia entre Weber e Windelband não era propriamente "amizade". Segundo Paul Honigsheim, Weber tinha aversão ao estilo de vida e ao conservadorismo exacerbado de Windelband. (II) Quanto a Rickert, Marianne Weber referiu-se à "amizade duradoura", e nunca rompida, que uniu os Weber e os Rickert. Cf. WEBER, Marianne. Weber: uma biografia. Niterói: Casa Jorge, 2003, p. 273. (III) Windelband estava ciente do drama de Simmel e chegou a se solidarizar com ele por escrito. Cf. WAIZBORT, Leopoldo. As aventuras de Georg Simmel. São Paulo: Editora 34, 2000, p. 557. (IV) Entre 1907 e 1908, quando se dá a frustrada tentativa de nomeação de Simmel para Heidelberg, e pela qual tanto se empenharam Weber e Georg Jellinek, Rickert ainda era professor em Freiburg. Ele não tinha, portanto, possibilidade alguma de interferir nos assuntos internos de uma outra universidade. Já Ringer, que reserva um capítulo inteiro à "adaptação de Rickert por Weber" (p. 45-69), demonstrou não ter, em absoluto, compreendido o primeiro. Seu tratamento impressionista da noção de individualidade histórica e da axiologia rickertiana, além da completa omissão da teoria da Begriffsbildung em Rickert não o recomendam como intérprete das influências recíprocas entre estes dois pensadores. O livro de Ringer foi também alvo da crítica contundente de Wilhelm Hennis, em resenha publicada no jornal Frankfurter Allgemeine Zeitung: "Der Fluch der Kröte. Fritz Ringer erklärt noch einmal Webers Methodologie" (FAZ, 27/08/1998).

5 CCCN: 107-119. 
para se perceber que a história não poderia continuar indefinidamente a ser considerada uma "ciência do espírito" no sentido estrito. Para Rickert a oposição fundamental entre os grupos de ciências não deve ser buscada no plano material (nível dos objetos), mas formal (nível lógico-conceitual).

Dilthey e Rickert conferem à história um lugar de primeira importância no conjunto das ciências humanas. Mas se Dilthey o faz na condição de historicista "pleno", ${ }^{6}$ é sobretudo na pesquisa histórica e nas suas características próprias que Rickert está interessado. Daí a importância da reflexão sobre os procedimentos-padrão de que se valem os historiadores. A despeito disso, praticamente não houve quem, nas últimas décadas, Ihe desse a devida atenção. Mais cômodo era assimilar noções como a de "disciplinas indiciárias" e virar as costas ao trabalho daqueles que, antes, deram à teoria da história uma contribuição bem mais sólida.

Rickert se defrontou, já na sua época, com tendências intelectuais similares às que hoje encontram ampla aceitação nos círculos acadêmicos. Na Alemanha, a Lebensphilosophie ganhava cada vez mais adeptos. ${ }^{7}$ A ciência era encarada com ceticismo crescente. O quadro apresentava-se de tal forma que, para o título das suas famosas conferências proferidas em Praga em 1936, Husserl não hesitou em usar a expressão "crise das ciências européias". Como Husserl, Rickert atribuía ao historicismo parte da responsabilidade por aquela primeira grande "crise" da ciência:

Tão logo é pensado até suas últimas conseqüências, o historicismo [...] revelase uma forma de relativismo e de ceticismo, e, como qualquer outro relativismo, se for levado a efeito de forma conseqüente, só pode conduzir a um total nilismo. $^{8}$

Rickert foi um dos mais importantes críticos daquela geração de críticos da ciência. Parece-nos não só útil, mas mesmo necessário, diante do quadro que se nos afigura no âmbito do pensamento histórico contemporâneo, retornar aos seus escritos e à sua força argumentativa, à sua invejável clareza de raciocínio, à sua defesa do ideal — não tenhamos medo da palavra — de ciência. Este retorno, consideramo-lo oportuno. Trata-se, em primeiro lugar, de tentar contrabalançar o efeito daquela reificação do problema da

6 REIS, José Carlos. Wilhem Dilthey e a autonomia das ciências histórico-sociais. Londrina: Eduel, 2003, p. 31

7 Não foi sem uma boa dose de sarcasmo que, no início dos anos 1930, Musil escreveu a respeito: „só em armazéns ainda se pode comprar alguma coisa sem filosofia da vida". MUSIL, Robert. O homem sem qualidades. Rio de Janeiro: Nova Fronteira, 1989, p. 183.

8 IPFH: 134-135. Os trabalhos de Frank R. Ankersmit mostram que uma evolução nesses termos nada tem de improvável. Em sua polêmica com Perez Zagorin, ele revela ter sido precisamente esse o caminho que trilhou. Caso Ihe fosse dado viver nos dias de hoje, não há dúvida de que também Rickert concordaria que "o pós-modernismo é a versão nominalista do historicismo". Cf. ANKERSMIT, Frank. Resposta a Zagorin. Topoi, n. 2, p. 153-173, 2001, p. 172 
compreensão apontada por Merz, e de restabelecer a devida importância da reflexão crítica no plano lógico e metodológico.

\section{Sobre a filosofia da história}

Que papel tem para Rickert a chamada filosofia especulativa da história? Ele crê serem duas as suas correntes principais: a metafísica e a sociológica/naturalista. Rickert não deixa de reconhecer em Hegel o mérito de ter fundado seu sistema sobre a vida histórica. Todavia, e nesse ponto sua aproximação com a escola histórica alemã é evidente, a questão principal estava em saber se um "sentido" ou um plano geral da história da humanidade seria de fato cognoscível. O sistema de Comte não lhe parece menos especulativo que o de Hegel. Só faz substituir o "sentido" pelas "leis" da história como o objetivo último da pesquisa. Com uma desvantagem adicional: o naturalismo comtiano ameaçava roubar à história sua autonomia enquanto disciplina, uma vez que ela deveria se limitar ao papel de mera auxiliar de uma "verdadeira" ciência da sociedade. Caso tivessem sido levadas em conta as conclusões que daí extrai Rickert, muitos dos conflitos em que se envolveu a pesquisa histórica no século XX provavelmente poderiam ter sido evitados: a conseqüência inevitável é que "se o naturalismo estiver com a razão, então a pesquisa histórica só se torna de fato possível sob a forma de sociologia" — alternativa que ele, é claro, não admite. Pois "a sociologia, como ciência generalizante, nunca poderá substituir a história". ${ }^{10}$ Haveria uma incompatibilidade insuperável entre método histórico e método naturalista, incompatibilidade para a qual não só Comte, mas boa parte dos historiadores não atentaram. Já o marxismo configurava, a seu ver, um exemplo de como o excesso de valorações práticas joga por terra um esforço que seus criadores acreditavam científico. O desprezo pelo papel das personalidades advinha, para Rickert, do fato de que, para o marxismo, só a multidão tem valor. Em lugar dos ideais da cabeça e do coração, o marxismo colocaria "os ideais do estômago". Tal forma de escrever a história seria "antes produto da política partidária que da ciência". ${ }^{11}$ Tratar-se-ia de uma perspectiva pouco apropriada por três razões: o marxismo nasce como parte indissociável de um programa político; ele subestima a importância dos fatores culturais; ele é pouco "objetivo". ${ }^{12}$

Oswald Spengler, por sua vez, estaria equivocado ao acreditar na originalidade metodológica de sua morfologia da história universal. Para Rickert, "a fundamentação lógica desta 'morfologia' (...) estava refutada já

9 GNWB: 11-12

10 GNWB: 201

11 CCCN: 118-119.

12 IPFH: 118-120. Voltaremos a este ponto mais tarde. 
muito antes de ser escrita". ${ }^{13}$ Refutação que ele, Dilthey e Weber haviam promovido por meio de seus ataques ao naturalismo nas ciências culturais. Ao pretender descobrir as leis do processo histórico, Spengler conferia a si mesmo um papel análogo ao de um "vidente". A oposição de Rickert a estas modalidades de filosofia da história não advinha apenas da constatação do que acreditava ser sua inviabilidade no plano epistemológico. A validade de tais teorias deveria ser questionada num nível ainda mais profundo:

Caso pudéssemos calcular antecipadamente o futuro em sua individualidade, e, portanto, soubéssemos exatamente tudo o que haverá de vir, então toda volição e todo agir perderia imediatamente seu sentido. Por conseguinte, temos razão para nos alegrar que não haja leis históricas. ${ }^{14}$

O que não significa que toda iniciativa neste campo seja destituída de sentido. Em resposta a críticas que Ihe fizera Troeltsch, Rickert admite que alguma forma de filosofia especulativa da história certamente se faz necessária. A reflexão no plano especificamente lógico-formal não esgota os problemas relativos à ciência histórica e aos processos por ela estudados. ${ }^{15}$ Rickert chegou a esboçar o projeto de uma disciplina sistemática, por ele concebida como uma filosofia da história que deveria tornar-se capaz, ela própria, de fazer jus à história e à sua estrutura lógica peculiar. A despeito de todo seu interesse, não teremos como nos ocupar com esta questão aqui; busquemos, antes, mostrar o que há de essencial em sua lógica do conhecimento histórico.

\section{A cientificidade da história}

Deixemos ao próprio Rickert a tarefa de apresentar o que seria o foco de suas preocupações: "Queremos conquistar para a lógica todo um terreno por ela desprezado, na medida em que nos perguntamos em que se baseia o conceito da história como ciência". ${ }^{16}$ Eis aí a primeira e desafiadora tarefa diante da qual ele se coloca. Nada mais nada menos que "compreender a essência da história como ciência". ${ }^{17}$

Observe-se que Rickert não tem em mente demonstrar a cientificidade da história, pois para ele está de antemão estabelecido que a história é uma "ciência". Isso exige de nós uma explicação preliminar. O termo Wissenschaft, traduzido normalmente como "ciência", manteve no alemão uma vocação bem menos restritiva que nas demais línguas ocidentais

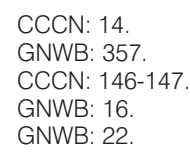


modernas. Quem quer que faça um estudo sistemático, seja em teologia, seja em estudos literários, seja em história, terá feito Wissenschaft. Em condições normais, a pretensão de que as disciplinas humanísticas ou a filosofia sejam unwissenschaftlich é estranha até mesmo para o cientista natural alemão. ${ }^{18}$

Mas esta generosidade da língua não parece ter sido suficiente. Também ali o anseio de fazer da história uma ciência "verdadeira", "rigorosa", foi recorrente. Verdadeira ciência? Sabemos bem o que isso normalmente significa: uma ciência generalizante, de leis, que siga fielmente o figurino das ciências da natureza.

Schopenhauer teria sido o primeiro a distinguir com clareza a oposição lógica entre história e ciência natural; porém, para Rickert, negar a cientificidade da pesquisa histórica acadêmica — como fizera o filósofo de Danzig ${ }^{19}$ — não passava de uma postura "dogmática". ${ }^{20}$ Afinal,

ninguém há de sustentar que seja particularmente feliz e acertada uma terminologia que não admite o nome de 'ciência' para a obra de Ranke e outros grandes historiadores. ${ }^{21}$

Em resumo, o que se contesta é que somente a perspectiva metodológica naturalista deva ser considerada científica; que, portanto, a história deva aderir a ela a fim de tornar-se uma "verdadeira ciência". Mais ainda: que o método naturalista possa ser o mais adequado para o estudo dos fenômenos histórico-culturais.

Vejamos um ponto fundamental em nosso autor. Segundo Rickert, o que diferencia a ciência de outras formas de conhecimento e percepção da realidade é o fato que a ciência elabora e opera conceitos..$^{22}$ Por que esta centralidade do conceito? Já em sua tese de doutoramento ele observa que o que distingue o homem pré-científico do homem de ciência é que o primeiro se contenta em dispor de um agregado de conhecimentos que sirvam às suas necessidades imediatas, enquanto que o segundo tende a extrair, daquele mesmo agregado, um sistema. ${ }^{23} \mathrm{O}$ conceito seria o instrumento $\mathrm{e}$ também, num certo sentido, o coroamento de tal esforço. Se naquela obra Rickert limita-se a analisar o processo de conceituação (Begriffsbildung) nas ciências jurídicas, nas ciências naturais e na matemática, tampouco deixa de lado dois pontos fundamentais para nossa discussão: (a) o modelo de

18 Cf. JONAS, Hans. Wissenschaft as Personal Experience. The Hastings Center Report, v. 32, n. 4, p. 27-35, 2002. 19 Para Schopenhauer a história "carece de sistema, tal como o há em qualquer das ciências. É um saber, não uma ciência, pois nunca conhece o particular por meio do geral". SCHOPENHAUER, Arthur. El mundo como voluntad y representación. Buenos Aires: El Ateneo, 1950, p. 484

20 GNWB: 169

21 CCCN: 60.

22 "Se conhecer é o mesmo que conceber, o resultado do conhecimento residirá no conceito" (CCCN: 40).

23 TD: 34 
formação de conceitos nas ciências naturais não tem de ser o mesmo para as demais ciências (rejeição do monismo); (b) o conceito é, em si mesmo, uma realidade dinâmica, na medida em que novas descobertas empíricas necessariamente devem levar a reformulações conceituais. Daí porque são "provisórios todos os conceitos empíricos". ${ }^{24}$

Estas questões foram discutidas em profundidade mais tarde, em sua alentada obra Os limites da formação de conceitos nas ciências naturais. Rickert crê ser impossível apreender a realidade diretamente, tal como ela é. A razão para isso é que realidade é infinitamente complexa e multifacetada. Ela é, para usar sua terminologia, "irracional". ${ }^{25}$ A função dos conceitos é, pois, reduzir essa complexidade. Eles são pontes sem as quais não se pode atravessar "o caudaloso rio da realidade". ${ }^{26}$ Nela selecionando o que há de essencial, eles tornam-na apreensível. O ponto-chave reside em identificar como as diferentes ciências elaboram seus conceitos. Só então estaremos em condições de saber o que confere à história a sua cientificidade.

\section{Os conceitos históricos e a questão dos valores}

O princípio básico fora introduzido por Windelband. A um grupo de ciências nomológicas se opõe um outro grupo de ciências, chamadas idiográficas. Esta divisão corresponderia aproximadamente à distinção entre ciências naturais e ciências históricas. Rickert entende que a noção de "lei" é uma noção-limite, pois nem toda ciência natural chega a elaborar ou descobrir leis. A oposição fundamental se dá, para ele, entre ciências generalizantes e ciências individualizantes. E é precisamente no plano conceitual que tal diferença se manifesta na sua forma por assim dizer pura. Diferentemente dos conceitos generalizantes das ciências da natureza, os conceitos históricos referem-se a realidades investidas de valor. O historiador, por exemplo, não busca um princípio geral de funcionamento, mas sim reconstituir individualidades.

Para o médico ou para o fisiologista, Goethe não passa de um 'exemplar'. Qualquer outro poderia ocupar o seu lugar sem prejuízo dos objetivos perseguidos pelo cientista natural. Ora, é desnecessário dizer que tal não poderia ser o caso nas ciências histórico-culturais. O exemplo mostra como a distinção entre ciência natural e história não deve ser buscada nos seus respectivos objetos. A mesma realidade "se torna natureza se a consideramos do ponto de vista do geral, [e] se torna história se a consideramos do

24 TD: 82

25 GNWB: 176. Esta "irracionalidade" do real tem no Funes de Borges a sua alegoria definitiva. O drama de Funes: devido à sua patológica compulsão a lembrar-se de tudo, toda e qualquer abstração lhe é vedada. A realidade só existe para ele como uma massa infinita e caótica de elementos individuais. 26 CCCN: 37 
ponto de vista do especial e do individual" ${ }^{27}$ Conceitos históricos deverão ser, pois, conceitos necessariamente individualizantes. ${ }^{28}$

Mas algo na idéia de conceito histórico resiste ao nosso entendimento. Se a história se ocupa antes de tudo com o estudo de individualidades, de singularidades, de fenômenos únicos, o que nos permite dizer que ela opera suas análises conceitualmente? ${ }^{29}$

Tudo passa a depender, evidentemente, do que se entende por "conceito". Um conceito pode ser considerado toda síntese, obtida à custa de esforço sistemático, daquilo que é essencial numa dada realidade. ${ }^{30}$ Rickert afirma existirem dois tipos de conceitos: conceitos simples e conceitos científicos. Os primeiros correspondem a elementos conceituais não definíveis (dados da percepção imediata, como as noções de "doce" ou "azul"). Os conceitos científicos, por sua vez, são "agregados" - seja de elementos conceituais, seja de outros conceitos científicos. ${ }^{31}$ Para Rickert, não existe qualquer diferença "entre o conteúdo de uma exposição científica em geral e o conteúdo do conceito". ${ }^{32}$ De modo que "um complexo de conceitos, que encerra o conhecimento científico de uma realidade, é o 'conceito' desta realidade". ${ }^{33}$

A esta altura, já estamos cientes das conseqüências do que é postulado acima. No plano estritamente lógico, nada nos impede de considerar uma exposição histórica como um conceito histórico. Da mesma forma que no conceito científico-natural, também aqui o que está em questão é reduzir a complexidade, a "irracionalidade" do real, por meio de uma seleção daquilo que nele tomamos por essencial. ${ }^{34}$

Significaria dizer que onde quer que haja uma exposição histórica, se pode falar legitimamente em ciência histórica? Rickert não chega tão longe.

27 GNWB: 173

28 É notável que os comentaristas (Aron, Merz, Oakes, Wöhler, Ringer) tenham evitado se aprofundar na questão dos conceitos históricos em Rickert. Isso se deve, a nosso ver, ao fato de que foram sociólogos e filósofos interessados em epistemologia das ciências sociais que se ocuparam com sua obra (entre historiadores, com a exceção de José Honório Rodrigues, não temos notícia de quem o tenha feito). Que o cientista social tenda a ver nos conceitos históricos rickertianos algo que eles não são, fica demonstrado em Merz, op. cit, p. 191-201. A visão do sociólogo está "contaminada" pela idéia de que conceitos sempre generalizam.

29 Para Martins pode-se falar, no máximo, em "categorias-períodos". A seu ver, quando se adota categorias em história, certo é que não se trata de categorias históricas. Cf. MARTINS, Estevão de Resende. O uso de categorias na ciência histórica. Leopoldianum, v. 10, n. 29, p. 5-24, 1983. Reis é de opinião semelhante: "o que seria "conceito histórico', já que a história é o lugar da mudança?". REIS, José Carlos. História \& teoria. Historicismo, modernidade, temporalidade e verdade. Rio de Janeiro: FGV, 2003, p. 125

30 CCCN: 83.

31 Um exemplo: a religião compreendida como "organização social das relações com a transcendência" (Thomas Luckmann).

32 Rickert define "exposição" (Darstellung) como o "emprego de conceitos para com eles formar novos conceitos" (CCCN: 40-41).

33 CCCN: 39.

34 GNWB: 225-226 
O problema da conceituação histórica está [...] em se é possível um rearranjo e uma simplificação científica da realidade sem que, simultaneamente, dela se perca - como é o caso das ciências naturais - a individualidade, e, todavia, não se forme uma mera 'descrição' de fatos, a qual ainda não deve ser vista como uma exposição científica. ${ }^{35}$

O que Rickert está a dizer é que a história não tem necessidade alguma de lançar mão de métodos ou conceitos generalizantes a fim de afirmar sua cientificidade. Ela é e prosseguirá sendo — conceitual e metodologicamente — uma ciência individualizante. Disso não destoaram sequer historiadores positivistas como Buckle e Lamprecht (suas obras principais não foram, respectivamente, uma História da Inglaterra e uma História da Alemanha?). A idéia mesma de "lei histórica", que de Comte a Hempel seduziu a tantos, não passa de uma contradictio in adjecto. ${ }^{36}$

Isso não significa dizer que a exposição científica se confunde com uma mera descrição. Nosso autor é bastante claro a esse respeito: "enquanto ciência, a história jamais pode residir numa mera descrição de fatos individuais". ${ }^{37}$ Onde está, pois, a diferença entre uma coisa e outra?

Façamos, antes, um breve excurso sobre a questão dos valores em Rickert. ${ }^{38} \mathrm{O}$ que verdadeiramente confere às ciências culturais em geral, e à história em particular, a sua especificidade é que elas são indissociáveis dos valores sociais. Distinguem-se dois tipos de valoração: a teórica e a prática. A primeira permite ao historiador eleger o que, em meio à massa de objetos, épocas ou personalidades que tem diante de si, deve ser considerado efetivamente relevante. Claro está que se trata de um construto intersubjetivo, mas que não implica qualquer "tomada de posição". Um pesquisador pode considerar a Revolução Iraniana de 1979 um evento relevante, sem que nisso entre em momento algum sua posição pessoal a respeito da mesma. Sem valoração teórica não há conceituação histórica (nos termos explicitados acima: composição de uma exposição histórica a respeito de um evento, processo ou figura individual), uma vez que sem ela não saberíamos sequer eleger o que é relevante. O problema da atribuição de historicidade é para Rickert — como o será para Weber — uma questão

35 GNWB: 231

36 GNWB: 175

37 GNWB: 234

38 Embora o título do artigo de Ferreira sugira que se vá tratar da teoria do valor em Windelband (!) e Rickert, a distinção fundamental entre valorações teóricas e valorações práticas não é mencionada. Toda a discussão fica comprometida por tomar como ponto de partida a perspectiva heideggeriana sobre o neokantismo. Cf. FERREIRA, Jonatas. A teoria do valor de Windelband e Rickert: fundamentos temporais de uma teoria do conhecimento. Estudos de Sociologia, v. 5, n. 2, p. 69-93, 1999. Christian Krijnen tornou evidentes os preconceitos e simplificações de Heidegger a respeito, e mostra que já Cassirer se dera conta disso após encontrar-se com Heidegger em Davos em 1929. Em carta enviada a Heidegger no mesmo ano, Rickert — que, aliás, fora seu orientador no doutorado - o repreende por difundir a idéia de que o neokantismo se reduziria apenas à epistemologia e nada teria a dizer sobre o "ser". Cf. KRIJNEN, Christian. Le sens de l'être. Heidegger et le néokantisme. Methodos, n. 3, 2003. Disponível em: http://methodos.revues.org/document116.html (acesso: 26.08.2005). 
de valores "universais", isto é, socialmente partilhados. ${ }^{39}$ A valoração prática, por seu turno, implica uma tomada de posição "contra" ou "a favor". Para ela não há, ao menos idealmente, lugar na ciência. ${ }^{40} \mathrm{~A}$ distinção entre estas duas modalidades pode ser ilustrada a partir de um exemplo dado por Rickert. Certamente concordaremos que há algo de errado com o historiador da arte caso ele só leve em conta em seus estudos aquilo que seu próprio gosto estabelece como "belo". Já o historiador científico "precisa se limitar ao que, contrariamente a uma valoração artística, podemos chamar de 'relação' teórica com o valor da arte". ${ }^{41}$

Uma vez resumido o ponto de vista de Rickert a esse respeito, podemos voltar à questão anteriormente colocada. O que, numa exposição histórica, nos permite caracterizá-la como "científica"? Podem-se enumerar três précondições: objetividade, contextualização e imputação causal. Quanto ao primeiro ponto, Rickert entende que "a história não é uma ciência valorativa, mas relativa a valores". ${ }^{42}$ Significa dizer que se os valores guiam as escolhas do historiador (valoração teórica), seus julgamentos (valoração prática) não interessam em absoluto à ciência. ${ }^{43}$ Rickert reconhece que nenhuma exposição histórica está "totalmente livre de valoração positiva ou negativa de seus objetos". Entretanto, ainda que a completa objetividade seja impossível, ela permanece para ele "um ideal lógico". ${ }^{44}$ O segundo ponto diz respeito ao fato de que o historiador deve não apenas descrever seu objeto; ele tem de relacioná-lo a um contexto (Zusammenhang), já que "somente a conceituação generalizadora [isto é, científico-natural] está atrelada a abstrações isoladas". ${ }^{45}$ Por fim, o historiador não pode abrir mão de investigar nos fenômenos históricos as redes causais que a eles se relacionam. Max Weber expressou bem esta preocupação de Rickert ao observar que o historiador que abre mão desta tarefa compõe "um romance histórico, não uma verificação científica" ${ }^{46}$ É um equivoco supor, porém, como fizeram os durkheimianos, que quem fala em causalidade fala, necessariamente, de "leis". O extremo oposto é igualmente enganoso: um nominalismo extremado, segundo o qual toda busca de causas estaria fadada ao fracasso. Rickert acredita que as ciências histórico-culturais não têm como deixar de

39 Abordamos a questão em MATA, Sérgio da. Max Weber e a ciência histórica. Teoria \& Sociedade (número especial) p. 150-171, 2005.

40 IPFH: 68-75.

41 GSP: 243-244

42 GNWB: 245

$43 \mathrm{O}$ que não quer dizer que juízos morais eventualmente não interessem ao historiador. A este respeito, ver as oportunas análises de HELLER, Agnes. Uma teoria da história. Rio de Janeiro: Civilização Brasileira, 1993, p. 141-152.

44 IPFH: 74, 68. Talvez fosse mais correto dizer que a objetividade, assim entendida, seja uma forma de ideal ascético. Numa passagem emblemática, Rickert afirma que "a questão diante da qual se vê colocado o pesquisador científico é a de que se ele está preparado para sacrificar sua visão de mundo à sua perspectiva teórica" (WPW: 343)

45 GNWB: 272

46 WEBER, Max. Objektive Möglichkeit und adäquate Verursachung in der historischen Kausalbetrachtung. In: Gesammelte Schriften zur Wissenschaftslehre. Tübingen: Mohr Siebeck, 1988, p. 279. 
investigar conexões causais. Também aqui vale o princípio da "seleção do essencial" a partir de valores, uma vez que o historiador nunca estará em condições de isolar todas as causas de um evento ou processo histórico. $\mathrm{O}$ que ele faz é selecionar e analisar as que considera significativas ${ }^{47} \mathrm{O}$ historiador que não se entrega a tal tarefa (os exemplos tornam-se cada vez mais freqüentes), em nome de um nominalismo radical, ignora que "o conceito de carência de causa de um fato não tem, por certo, sentido algum para a ciência empírica". ${ }^{48}$

\section{A generalização a serviço do singular}

Estamos diante de um autor que tem ainda muito a nos dizer, a nós, historiadoras e historiadores do século XXI. E isso porque alguns de nossos dilemas teórico-metodológicos atuais não são tão "atuais" assim. A Droysen renaissance dos últimos anos mostra em que medida o estudo da obra daqueles que, no oitocentos, refletiram sobre tais dilemas, permite obter um ganho real no que diz respeito ao nosso entendimento dos complexos problemas que envolvem a teoria e a lógica do conhecimento histórico.

Ao primeiro contato com os escritos de Rickert, entretanto, tem-se a impressão de que nos encontramos diante de uma contradição, difícil de superar, entre sua veemente recusa do historicismo e sua argumentação no sentido de que a história é sempre a ciência do individual ${ }^{49}$ Vítima desta impressão, Raymond Aron afirmou que em Rickert encontramos "l'interprétation et la justification logique de l'histoire traditionnelle, celle qui reconstitue une suite intelligible d'événements singuliers". 50 Na verdade, trata-se, para ele, de questões colocadas em planos distintos: uma coisa é o historicismo enquanto visão de mundo; outra, bem diferente, a essência lógica do trabalho histórico. Aos seus olhos, esta é um princípio insuperável; e aquela, um absurdo.

Mas o que dizer de campos de pesquisa, como a história econômica e social, em que a existência de permanências e regularidades é inegável? Ninguém, em sã consciência, defenderia a idéia de que a revolução da ciência histórica no século XX teria ocorrido sem o intenso diálogo com disciplinas com forte pendor "generalizante", tais como a economia e a sociologia. Quando Theodor Schieder observa, em meados da década de 1960, que as diferenças entre a formação de conceitos nas ciências naturais e nas ciências culturais já não era tão grande como "há cinqüenta anos", ${ }^{51}$ é de uma aparente inadequação da teoria rickertiana à ciência histórica

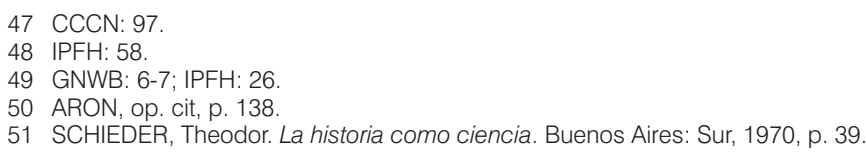


praticada em meados do século XX que se fala. De fato, a utilização de métodos quantitativos e a difusão da "história serial", os modelos de uma história "total" (à la Braudel) ou "estrutural" (à la Conze), tudo isso parecia contradizer a tese fundamental de Rickert. Eram os tempos do crepúsculo da narrativa e do acontecimento.

Seria demasiado fácil demonstrar as afinidades eletivas entre a filosofia crítica da história de Rickert e o momento imediatamente posterior: o do "retorno" da narrativa e do acontecimento. Seja como for, importa perceber que ele, muito provavelmente, estava atento ao fato de que a história da ciência histórica é marcada por movimentos pendulares desta ordem. Rickert sabia bastante bem que a historiografia de seu tempo já não era nem podia ser a de Ranke. Seu íntimo contato com os escritos de Weber, bem como seu conhecimento das polêmicas historiográficas de então, sugeriam a adoção de uma posição mais matizada que a de Windelband, para o qual há uma oposição insuperável entre método individualizante e método generalizante. Rickert admite que talvez fosse possível demarcar

alguns territórios determinados em cuja exposição a história não chega a bom termo sem conhecimentos científicos de conceitos universais [...]. É bem possível que na futura ciência da história os conceitos formados de modo naturalista, ou seja, científico-generalizador, tenham na exposição dos processos singulares e individuais um papel mais importante e também mais feliz do que hoje. ${ }^{52}$

Não obstante, é preciso ter em conta que "por muito que chegue o historiador a utilizar as ciências generalizadoras, estas nunca poderão ser fundamentais para ele". ${ }^{53}$

\section{O conceito de cultura em Rickert}

Em Rickert os termos "ciências culturais" e "ciências históricas" são empregados como sinônimos. Eis porque, para ele, não há historiador que não seja historiador da cultura. Voltaremos a este ponto adiante. Importa mostrar, por hora, o que Rickert entende por cultura.

Embora E. B. Tylor tivesse publicado seu Primitive Culture vinte e cinco anos antes de vir a público o primeiro volume do livro de Rickert sobre os limites da formação de conceitos nas ciências naturais, a acepção hodierna de cultura, que tanto deve a Tylor e ao próprio historicismo alemão, estava longe de ser uma unanimidade. "Cultura", em Rickert, é, antes de mais nada, uma denominação abrangente para todo um conjunto de fenômenos

52 CCCN: 73.

53 CCCN: 74. À mesma conclusão chegará Ginzburg: "Mesmo que o historiador não possa deixar de se referir, explícita ou implicitamente, a séries de fenômenos comparáveis, a sua estratégia cognoscitiva assim como os seus códigos expressivos permanecem intrinsecamente individualizantes". GINZBURG, Carlo. Mitos, emblemas, sinais. São Paulo: Cia. das Letras, 1991, p. 156-157. 
alheios ao universo da natureza. Esta forma um tanto peculiar de conceber a cultura, e que tanto se aproximava da de Weber, ${ }^{54}$ foi resumida nestes termos: "por 'cultura' compreendemos o fenômeno investido de sentido (das sinnerfüllte Sein) e possuidor de significado (Bedeutung), não para indivíduos isolados, mas para a sociedade na qual se origina, e que por tal razão se torna historicamente 'essencial'". ${ }^{55}$

É cultural qualquer realidade investida de sentido, valorada. De modo que - nesta acepção mais abrangente - também o historiador político trata de "cultura". Os valores especificamente culturais são forças coletivas, socialmente abrangentes e dotadas de caráter normativo. São o produto de instituições religiosas, políticas, jurídicas, artísticas e científicas. ${ }^{56}$ Como vimos anteriormente, somente a partir deles é possível distinguir o que (ou quem) é de importância histórica do que (ou quem) é historicamente "irrelevante". Daí porque o debate entre história política e história cultural, travado em fins do século XIX, não chega a interessar diretamente a Rickert. Tal debate

não pode ser decidido pela lógica e não se estende tampouco à questão da essência do método histórico. Se de alguma forma se deseja falar da oposição entre história política e história cultural, então se verá que ambas hão de empregar o mesmo procedimento individualizador, relativo a valores. ${ }^{57}$

Fundamentando-se antes em pressupostos formais (lógico-conceituais) que materiais (as características próprias deste ou daquele objeto), a acepção rickertiana de cultura adquire uma vocação tão ecumênica quanto o conceito de cultura que viria a ser desenvolvido pela antropologia norteamericana ${ }^{58} \mathrm{O}$ que não significa dizer que se estivesse a defender uma espécie de panculturalismo, como o que se nos defronta nos dias de hoje. Criticar o naturalismo no campo dos estudos históricos, como fez Rickert tão obstinadamente, era antes de mais nada uma maneira de restaurar a dignidade própria dos fenômenos sociais. Seria o caso de perguntar se o panculturalismo não terá incorrido no mesmo erro, apenas numa direção oposta, conduzindo-nos a um novo monismo, tão redutor quanto aquele

54 Cf. MATA, Sérgio da. Alguns comentários sobre Max Weber e a história. In: DIEHL, Astor A. Max Weber e a história. Passo Fundo: UPF Editora, 2004, p. 122-123.

55 GSP: 270-271. Uma primeira formulação pode ser encontrada em CCCN: 30

56 GNWB: 393

57 IPFH: 89. Não era exatamente esta a posição de Gothein, que, num ensaio clássico, propôs uma distinção clara entre os procedimentos "sintéticos" da história política e os "analíticos" da história cultural. Enquanto a primeira centra sua atenção nos eventos, a segunda priorizaria os processos. Cf. GOTHEIN, Eberhard. Die Aufgaben der Kulturgeschichte. Leipzig: Duncker \& Humblot, 1889, p. 12-13.

58 Cujas origens, como mostrou Sahlins, remontam ao historicismo alemão e, em especial, a Herder. Cf. SAHLINS, Marshall. O "pessimismo sentimental" e a experiência etnográfica: por que a cultura não é um "objeto" em via de extinção. Mana, v. 3, n. 1, p. 41-73, 1997. 
outro, o qual tudo pretendia subsumir sob o conceito de natureza. ${ }^{59}$ Para reducionismos dessa espécie não foram talhados os conceitos de "natureza" e de "cultura" em Rickert. Mais: ao estabelecer uma íntima relação entre valores culturais (Kulturwerte) e instituições, ele nos alertava para o fato de que a cultura nunca se produz e reproduz por si mesma. Isso nos ajudaria a evitar a tendência, igualmente difundida atualmente, de se avaliar os processos culturais como realidades autônomas e mesmo indeterminadas. Tentação que a sociologia crítica da cultura tem chamado "essencialismo culturalista". ${ }^{60}$ Ainda assim, o antropólogo ou o historiador cultural contemporâneos provavelmente ficarão um tanto desapontados com as considerações de Rickert sobre a cultura. Afinal, não se trata de uma categoria central no seu sistema? Queremos crer que tais limitações não escaparam ao próprio Rickert. De passagem, ele admite que a tarefa ainda estava por ser feita: "o progresso essencial nas ciências culturais [...] depende do progresso que se realizar na elaboração de um conceito objetivo e sistematicamente organizado de cultura" . ${ }^{61}$

\section{Ciência histórica e arte}

A palavra "crise" goza de um fascínio inegável, e o simples bom senso ensinaria a ver no seu emprego o fruto de uma tentação à qual normalmente cedemos com demasiada facilidade. Evidentemente, não nos passa pela cabeça atribuir a atual tendência à "poetização do conhecimento histórico" (Rüsen) apenas a momentos de crise, supostos ou reais. Que a reflexão a respeito está longe de ser recente, demonstram-no os escritos de Luciano de Samosata, Wilhelm von Humboldt e Ranke. ${ }^{62}$

Ainda que a questão não se colocasse de forma tão espetacular quanto nos últimos anos, as relações entre história e arte foram amplamente discutidas na Alemanha de Rickert. Em 1874, no seu discurso de posse como reitor da Universidade de Berlim, Theodor Mommsen defendera a idéia de que o historiador "tem seu lugar antes entre os artistas que entre os eruditos". Na esteira de Nietzsche e Burckhardt, considerações deste tipo tornavam-se cada vez mais freqüentes. Em Ranke identificava-se não simplesmente o princeps historicorum, mas o "esteta" (Yorck), o "grande

59 Flusser sintetizou esta inclinação ao propor que, dada a sua "vacuidade", seria chegada a hora de abandona o conceito de natureza. FLUSSER, Vilém. Natural:mente. Vários acessos ao significado de Natureza. São Paulo: Duas Cidades, 1979, p. 140.

60 Remetemos o leitor aos brilhantes trabalhos de Jessé Souza. É interessante notar que crítica de idêntico teor fol feita, em fins da década de 1940, por Oliveira Vianna.

61 CCCN: 144-145. As dificuldades aqui são, sem dúvida, imensas. Ver SOEFFNER, Hans-Georg. Kulturmythos und kulturelle Realität(en). In: Gesellschaft ohne Baldachin. Weilerswist: Velbrück, 2000

62 Em sua História da França, publicada entre 1852 e 1861, ele observa: "A tarefa do historiador é ao mesmo tempo erudita e literária, pois a história é simultaneamente arte e ciência". RANKE, Lepold von. The Secret of World History. Selected Writings on The Art and Science of History. New York: Fordham University Press, 1981, p. 258 (devo ao Prof. Valdei Araújo o acesso a esta útil coletânea dos escritos de Ranke). 
artista" (Dilthey). Houve quem visse na História Alemã no século XIX, de Treitschke, "uma façanha poética" (Borchardt). Que tais concepções fossem caras ao círculo de Stefan George, é um tanto óbvio: seu discípulo Friedrich Gundolf referiu-se a Ranke, Mommsen e Burckhardt como os que, no século XIX, "mais se aproximaram da verdadeira tarefa do poeta". Oswald Spengler, autor cuja influência no pós-guerra não estamos no direito de subestimar, afirmou que "a concepção do mundo como história tem suas raízes no terreno artístico". ${ }^{63}$ A história, conhecimento que ele classificava como fisiognômico, não se diferenciaria da poesia. Foi como poeta, aliás, que ele próprio se definiu ao fim de um encontro com Max Weber.

Precisamente Weber foi o responsável pela deflagração de um amplo debate a respeito. Em 1917 ele profere sua famosa conferência A ciência como vocação, publicada dois anos mais tarde. ${ }^{64}$ Weber diagnostica a ânsia da juventude de sua época pela experiência viva, o que a ciência, em sua aparente frieza, não estaria em condições de propiciar. De fato, diz ele, o cientista não é menos movido pela paixão que o artista. Weber vai mais longe: tanto para um quanto para o outro a "inspiração" é fundamental. Mas as semelhanças param por aí. Aquele que se orienta apenas pela inspiração não é o homem de ciência, mas o diletante. ${ }^{65}$ Por sua vez, o produto da inspiração - a idéia - só se torna produtivo em mãos daquele que dispõe de um método de trabalho (Arbeitsmethode) ${ }^{66} \mathrm{~A}$ diferença fundamental entre arte e ciência residiria no fato de que a obra de arte autêntica nunca se torna antiquada, enquanto que a ciência suscita sempre novas perguntas e, assim, "quer ser superada e envelhecer". ${ }^{67}$

Podemos especular que não foi sem certo incômodo que Rickert fez sua intervenção nesse debate. Ele tinha sido o responsável pelo primeiro contato de Weber com a obra de Stefan George, e consta que teria mesmo pedido ao poeta que lhe enviasse alguns de seus poemas. ${ }^{68}$ Some-se a isso que seu mestre Windelband considerava como tarefa da ciência histórica "infundir vida nova a uma forma ou figura do passado". Nesse sentido, o historiador somente se diferenciaria do artista pelo fato de que este último

63 SPENGLER, Oswald. A decadência do Ocidente. Rio de Janeiro: Zahar, 1973, p. 93

64 WEBER, Max. Wissenschaft als Beruf. In: Gesammelte Schriften zur Wissenschaftslehre. Tübingen: Mohr Siebeck, 1988, p. 582-613.

65 Novamente, são claras as semelhanças com Rickert: "Na ciência não pode haver conhecimento puramente intuitivo" (TD: 42)

66 Mais tarde, Husserl viria a se expressar em termos praticamente idênticos: "A descoberta é um misto de instinto e método" (Entdeckung, das ist eine Mischung von Instinkt und Methode). Cf. HUSSERL, Edmund. Die Krisis der europäischen Wissenschaften und die transzedentale Phänomenologie. Hamburg: Felix Meiner, 1996, p. 42. Diferentemente de Rickert, a ambivalência de Weber a este respeito é flagrante. Em A ciência como vocação, tudo sugere que ele concorda com Rickert quando este último afirma que "sem método não há ciência" (MPU: 108). Numa das preleções que deu pouco antes de sua morte, porém, Weber afirmou: "O método é a coisa mais estéril que existe: com método, somente, nunca se criou nada". Citado por HENNIS, Wilhelm. Max Weber und Thukydides. Tübingen: Mohr Siebeck, 2003, p. 157.

67 No original: "jede wissenschaftliche ,Erfüllung' bedeutet neue ,Fragen' und will ,überboten ' werden und veralten". WEBER, op. cit., p. 592

68 LEPENIES, Wolf. As três culturas. São Paulo: Edusp, 1996, p. 266 
procura dar vida àquilo que existe somente em sua imaginação. Para Windelband, tal como no caso do representante das belles lettres, o pensamento do historiador obedeceria ao princípio da "plasticidade". 69

Para Rickert o historiador pode expor uma realidade individual lançando mão de imagens suscitadas pela intuição. É o que explica porque tantas vezes se vê, no historiador, o artista. Esse "parentesco" é fato — na ciência histórica existem inegáveis "momentos artísticos". ${ }^{70}$ Porém, ele considera que a intuição tem uma importância secundária na ciência histórica: "afirmar que a história é uma arte [...] não nos diz absolutamente nada sobre o método da história". 71

A arte tende a apreender no mundo o que há de universal. Ela procede, portanto, de maneira oposta à da história. Rickert toma o caso de uma expressão artística peculiar, o romance histórico. O que nele há de reprodução de realidades históricas individuais não Ihe é essencial do ponto de vista estético. Se o valor artístico intrínseco de um quadro, para tomar outro exemplo, não se mede por sua (eventual) semelhança com o real, "tampouco o valor estético de um romance reside na fidelidade com que reproduz os fatos históricos"..$^{72}$ Rickert admite que muitas narrativas históricas foram alçadas por seus autores à condição de obras de arte. Mas ainda assim a diferenciação se mantém: o essencial na arte é a intuição, e na história, o conceito. Num trabalho histórico devem-se eventualmente levar em consideração as qualidades estéticas; mais decisivo, porém, é o grau de semelhança entre o real e a sua representação na narrativa. Não resta dúvida que o historiador pode e deve recorrer à sua intuição a fim de reconstruir um dado objeto - contando que sua exposição seja verdadeira. "É precisamente esta verdade histórica o que a obra de arte não leva em consideração" ${ }^{73}$

Antes de entregar-se à fase de seu trabalho que tem relativa afinidade com o proceder do artista, e "antes de revestir seus conceitos com intuições", o historiador terá de ter superado dois outros momentos da pesquisa: com quais objetos deve ele se ocupar? O quê, no âmbito de seu objeto, deverá ser considerado essencial? Sem um a priori qualquer, tais escolhas

69 A versão em castelhano induz a erro quando traduz Anschaulichkeit por "instinto". Os correlatos que consideramos mais próximos do sentido original seriam "plasticidade", "expressividade". Cf. WINDELBAND, Wilhelm. Pre/udios filosóficos. Buenos Aires: Santiago Rueda, s/d, p. 321

70 LWKW: 64.

71 CCCN: 78.

72 CCCN: 79.

73 CCCN: 80. Rickert não considera o "realismo" um empecilho aos seus argumentos, pois para ele nem a arte nem a ciência são capazes de oferecer uma reprodução ou duplicação exata da realidade (CCCN: 77). Em seu importante estudo sobre o romance histórico, ao examinar aquilo que ele prefere chamar de "relatividade", Lukács desenvolve um raciocínio idêntico ao de Rickert: "A purely intellectual reflection of facts or laws of objective reality may openly admit this relativity [isto é, seu caráter necessariamente incompleto: SM] and must in fact do so [...] It is quite different with art. Obviously, no literary character can contain this infinite and inexhaustible wealth of features and reactions to be found in life itself. But the nature of artistic creation consists in the ability of this relative, incomplete image to appear like life itself, indeed in a more heightened, intense and alive form than in objective reality". LUKÁCS, Georg. The Historical Novel. Middlesex: Penguin, 1981, p. 104. 
são impossíveis. Segundo Rickert, "somente com este a priori, com este 'préjuízo', [o historiador: SM] conseguirá dominar a continuidade heterogênea do suceder real por meio de conceitos". ${ }^{74}$ Eis a razão pela qual, conclui, o historiador não tem necessariamente de lançar mão de meios artísticos para resolver problemas científicos.

\section{Rickert e a "crise" da ciência}

Vimos que toda a discussão em torno da "crise" da ciência não chega a ser novidade, em especial num país como a Alemanha. Nas primeiras décadas do século passado, ali grassava o solipsismo. "Toda história é lenda", afirmava o historiador diletante Egon Friedell. Pensadores das mais distintas tendências alertavam para os riscos do "desencanto diante da civilização" (Plessner), da "rebelião contra a ciência" (Troeltsch), da "destruição da razão" (Lukács). Na Alemanha, em grande parte, este estado de coisas foi o subproduto da violenta crise intersubjetiva de sentido que se abateu sobre o país após a derrota na primeira grande guerra. ${ }^{75}$ Para isso parece ter contribuído também o isolamento internacional a que foi submetida sua comunidade científica no pós-1918. Um retrato da situação foi feito em 1922 por Adolf von Harnack, o grande historiador do cristianismo:

Mais uma vez uma onda romântica internacional assola nossa pátria, ou melhor, toda a paisagem cultural européia. Em vez de 'ciência', chama-se 'vida'; em vez de 'razão', 'intuição', enquanto uma visão de mundo repleta de forças misteriosas e de elementos que enlevam a alma compensaria o espírito pelo suposto colapso de todo o conhecimento racional. ${ }^{76}$

Há pouco fizemos referência à polêmica causada por $A$ ciência como vocação - um texto que, em si mesmo, é um claro indicativo do quadro a que se refere Harnack. A discussão se estendeu por vários anos, mesmo após a morte de Weber. Nela tomariam parte nomes como Ernst Robert Curtius, Erich von Kahler, Artur Salz e Troeltsch. Este último atribuiu a intensidade da "crise" na Alemanha ao fato de ser ela a "terra natal da historiografia moderna" e à derrota na guerra. ${ }^{77}$

A posição de Rickert foi expressa num artigo originalmente publicado em 1922 na revista japonesa Kaizo. Reformulado e expandido, o texto reaparece, dois anos mais tarde, nas páginas de Logos. Rickert deixa claro o quanto suas posições estavam próximas das de Weber. Também para ele,

74 CCCN: 82

75 Tomamos este conceito do sugestivo ensaio de BERGER, Peter; LUCKMANN, Thomas. Modernidade, pluralismo e crises de sentido. Petrópolis: Vozes, 2004.

76 Citado por STERN, Fritz. O mundo alemão de Einstein. São Paulo: Cia. das Letras, 2004, p. 64.

77 TROELTSCH, Ernst. Die Krisis des Historismus. In: VOIGT, Friedemann (Hrsg.) Ernst Troeltsch Lesebuch. Tübingen: Mohr Siebeck, 2003, p. 260. 
o termo "vocação" define bem a situação ideal daquele que se devota ao trabalho de pesquisa científico.

A idéia de "crise" pecaria por falta de originalidade: "freqüentemente e desde sempre a ciência teve seus inimigos, e também a forma de luta que contra ela se mantém hoje lembra movimentos espirituais de séculos passados". ${ }^{78}$ Se a crítica à ciência já estava colocada desde os tempos de Goethe e até mesmo antes, parece-lhe que a ascendência principal deve ser atribuída a Nietzsche. Desde então "nunca se calou totalmente entre nós a desconfiança em relação à ciência". ${ }^{79}$ Como Troeltsch, ele considera que o movimento anti-científico fortalecera-se desde a débâcle de 1918.

Weber fizera menção ao que suscitava a crítica: a ciência nada nos falaria sobre o "vivido". Rickert concorda que a ciência não pode se referir a totalidades já que, inevitavelmente, tem de subdividir a realidade a fim de estudá-la. A crítica, por sua vez, não estava disposta a admitir tal necessidade, pois movia "uma luta de morte contra toda visão da vida que se oriente apenas pela razão". ${ }^{80}$ Mas uma outra questão antecede, no entender de Rickert, todas as demais: aquele que se engaja nesta discussão deve deixar de lado toda ilusão de que estaria apto a convencer seus oponentes.

Caso alguém queira 'libertar' seu espírito a um ponto tal que, como Nietzsche, dispense a crença na verdade, então não há possibilidade de entendimento científico com ele. ${ }^{81}$

Sem alguns consensos prévios, portanto, não há qualquer possibilidade de avançar. Rickert defende dois. Primeiro, o ideal da verdade é um valor do qual a ciência não pode abrir mão (ele é, se assim podemos nos expressar, o mais valioso dos valores). ${ }^{82}$ Segundo, a ciência é apenas um dos campos de uma cultura; ela não tem como nos dar "tudo". 83

Conhecer o sentido e os limites da ciência requer, como propusera Weber, um retorno aos seus primórdios, à Grécia Antiga. Talvez assim se poderia dizer algo a respeito da "essência" da ciência. Foram três os traços essenciais daquela nova postura diante do mundo introduzida pelos

78 LWGP: 154

79 LWGP: 154. No âmbito da filosofia propriamente dita, a seu ver, o ensejo de realizar grandes sistematizações dera lugar à paradoxal idéia de que o progresso estaria num retorno ao estágio pré-científico (TD: 34). As homologias com o pensamento pós-moderno são evidentes. A esse respeito, cf. MATA, Sérgio da. Antropologia, história e "supermodernidade". Locus, v. 4, n. 1, p. 133-136, 1998.

80 LWGP: 157

81 LWGP: 158

82 Este não é o lugar adequado para discutir o problema da verdade em Rickert. Observemos apenas que ele tem plena consciência de que a verdade histórica tem a sua peculiaridade. As exposições históricas, afirma, "não guardam relação alguma com uma verdade absoluta". O que não colocaria a ciência histórica numa situação inferior à das ciências naturais: "não é uma objeção contra a cientificidade da história o dizer que ela deve ser constantemente reescrita, pois tal é a sorte comum de todas as ciências" (CCCN: 142; grifo nosso).

83 Em seu livro sobre Kant, ele esclarece este ponto: "Estabelecer o valor teórico como o mais elevado de todos os valores é incompatível com uma filosofia verdadeiramente abrangente da cultura [...] moderna". Citado por RINGER, Fritz K. O declínio dos mandarins alemães. São Paulo: Edusp, 2000, p. 341. 
filósofos gregos: eles operaram uma inversão radical na medida em que, a partir de então, o homem não apenas aprende para viver, mas vive para aprender. Surge assim o "homem teórico". ${ }^{84}$ Segundo, não se trata apenas de conhecer, mas de estabelecer relações. O conhecimento das relações não deve recorrer ao (ou se confundir com o) mito. E, terceiro, o homem grego foi o responsável pela descoberta do conceito. Seriam estas as três dimensões básicas da ciência grega que chegaram até nós. ${ }^{85}$

O problema dos críticos da ciência é que eles não raro esbarram numa situação por assim dizer aporética, ao apoiarem sua negação em argumentos (para)científicos. Para Rickert

Onde se combate, com base em teorias filosóficas da vida, a pesquisa teórica como inimiga da vida, ali fala sempre um homem teórico [...]. Ele utiliza argumentos teóricos para, com seu auxílio, declarar guerra a toda ciência. ${ }^{86}$

A idéia de que o homem teórico ou a ciência estariam mortos se ampara, a seu ver, menos numa concepção histórica que naturalista. Sob esta última perspectiva, a ciência, como também outros aspectos da cultura, poderiam ser analisados à maneira de um ser vivo. Uma dinâmica feita de nascimento, desenvolvimento e morte. Não é precisamente este o raciocínio por detrás da crença no "fim da ciência"? É evidente, diz Rickert, que realidades e mesmo povos inteiros possam perecer; o mesmo, porém, não valeria para alguns dos bens culturais que nos foram legados através dos séculos. A ciência seria uma destas conquistas definitivas. Dada a "irritante falta de clareza" daquela geração de críticos da ciência, Rickert mostra-se menos interessado em buscar um sentido unívoco para o termo "vida" — os próprios adeptos da Lebensphilosophie não teriam logrado atingir tal objetivo - que falar das condições sob as quais se pode efetivamente falar em vida da ciência:

Ela [a ciência] [...] vive somente quando estabelece conhecimentos verdadeiros, e para isso sempre se fazem novamente necessários homens da espécie dos que surgiram pela primeira vez na Grécia. ${ }^{87}$ 


\section{SIGLAS DAS OBRAS DE RICKERT UTILIZADAS}

TD - Teoría de la definición. México: Universidad Autónoma Nacional de México, 1960 (1ª edição: 1888).

GNWB - Die Grenzen der naturwissenschaftlichen Begriffsbildung. Eine logische Einleitung in die historische Wissenschaften. Tübingen: J. C. B. Mohr, 1921 (1ª edição: 1896-1902).

CCCN - Ciencia cultural y ciencia natural. Madrid: Calpe, 1922 (1ª edição: 1899).

IPFH - Introducción a los problemas de la filosofía de la historia. Buenos Aires: Nova, 1961 (1ª edição: 1905).

LWKW - Lebenswerte und Kulturwerte. In: BAST, Rainer A. (Hg.) Heinrich Rickert. Philosophische Aufsätze. Tübingen: Mohr Siebeck, 1999 (1ª edição: 1911).

LWGP - Das Leben der Wissenschaft und die griechische Philosophie. In: BAST, Rainer A. (Hg.) Heinrich Rickert. Philosophische Aufsätze. Tübingen: Mohr Siebeck, $1999\left(1^{\mathrm{a}}\right.$ edição: 1924).

MPU - Das Methode der Philosophie und das Unmittelbare. In: BAST, Rainer A. (Hg.) Heinrich Rickert. Philosophische Aufsätze. Tübingen: Mohr Siebeck, 1999 (1ª edição: 1924).

GSP - Geschichte und System der Philosophie. In: BAST, Rainer A. (Hg.) Heinrich Rickert. Philosophische Aufsätze. Tübingen: Mohr Siebeck, 1999 (1ª edição: 1932).

WPW - Wissenschaftliche Philosophie und Weltanschauung. In: BAST, Rainer A. (Hg.) Heinrich Rickert. Philosophische Aufsätze. Tübingen: Mohr Siebeck, 1999 (1ª edição: 1933). 